\title{
Bimetallic Au-Pd and Ag-Pd Clusters Synthesised by $\gamma$ or Electron Beam Radiolysis and Study of the Reactivity/Structure Relationships in the Selective Hydrogenation of Buta-1,3-Diene
}

\author{
T. Redjala ${ }^{1}$, H. Remita' ${ }^{1}$, G. Apostolescu' ${ }^{1}$, M. Mostafavi ${ }^{1}$, C. Thomazeau ${ }^{2}$ and D. Uzio ${ }^{2 *}$ \\ 1 Laboratoire de Chimie Physique, UMR 8000, Université Paris Sud XI-CNRS, Bât. 349, 91405 Orsay - France \\ 2 Institut français du pétrole, IFP, Direction Catalyse et Séparation, IFP-Lyon, BP 3, 69390 Vernaison - France \\ e-mail: tanafit.redjala@etu.ensp.fr - hynd.remita@lcp.u-psud.fr - gabriella.apostolescu@lcp.u-psud.fr - mehran.mostafavi@lcp.u-psud.fr \\ cecile.thomazeau@ifp.fr - denis.uzio@ifp.fr
}

\begin{abstract}
Résumé - Agrégats bimétalliques Au-Pd et Ag-Pd synthétisés par réduction radiolytique : étude des relations réactivité/structure en hydrogénation sélective du buta-1,3-diène - Des catalyseurs Ag-Pd et Au-Pd (sous forme d'alliage ou de structure cœur-coquille) ont été synthétisés par réduction radiolytique (rayons gamma ou faisceau d'électrons). L'étude de l'hydrogénation sélective de buta-1,3diène par ces différents nanoagrégats déposés sur alumine a permis de déterminer les effets de la composition et de la structure sur les performances catalytiques. Les nanoagrégats $\mathrm{Au}-\mathrm{Pd}$ et $\mathrm{Ag}-\mathrm{Pd}$ montrent des propriétés catalytiques très différentes : alors que l'activité en hydrogénation est modifiée dans des systèmes Au-Pd sans changement de sélectivité dans la formation des butènes, d'importantes variations de sélectivité sont observées pour les nanoagrégats Ag-Pd déposés sur alumine.
\end{abstract}

Abstract - Bimetallic Au-Pd and Ag-Pd Clusters Synthesised by $\gamma$ or Electron Beam Radiolysis and Study of the Reactivity/Structure Relationships in the Selective Hydrogenation of Buta-1,3-Diene $A g-P d$ and $A u-P d$ (alloyed or core-shell) catalysts were synthesised by radiolytic reduction (gamma rays or electron beam). Selective hydrogenation of buta-1,3-diene was performed with these different nanoparticles deposited on alumina in order to investigate composition and structure effects on catalytic performances. Au-Pd and Ag-Pd nanoparticles exhibit very different catalytic behaviours: whereas only hydrogenation activity is modified on Au-Pd systems without any change in selectivity toward butenes formation, important variations in selectivity into butenes are observed for Ag-Pd nanoparticles deposited on alumina support. 


\section{INTRODUCTION}

Nanoscale materials such as multimetallic nanoparticles, particularly when intimately alloyed, are today of great importance due to their diverse range of electrical, optical and catalytic properties [1-2]. Bimetallic nanoparticles often exhibit enhanced catalytic reaction performances, mainly in terms of selectivity and stability, compared to the separate components [3-6]. Palladium-based bimetallic catalysts have been developed for many years in order to increase the selectivity of the hydrogenation of polyunsaturated hydrocarbons, reaction used to produce highly purified olefin cuts. For instance in the $\mathrm{C} 4$ streams, the residual concentration of the main impurity, buta-1,3-diene, must be lower than 5 ppm for polymer grade specification. Much attention has been paid to the study of AgPd [7-8] and AuPd [9-10] systems which have been found to be more efficient catalysts compared to monometallic ones for hydrogenation of alkynes and dienes of the different hydrocarbon effluents.

In this paper we present and discuss the catalytic properties of Au-Pd and Ag-Pd bimetallic nanoparticles produced by $\gamma$ or electron beam radiolysis and deposited on alumina carrier. The effect of the structure (core-shell or alloyed) on catalytic performances was studied. The activity and selectivity of the bimetallic catalysts were also compared to that of a monometallic Pd conventional catalyst prepared via deposition / precipitation of mineral precursor.

Radiolytic reduction of metal ions in aqueous solutions is a clean process to synthesise metal nanoparticles. The hydrated electrons and the reducing radicals produced during the radiolysis of the solvent are used to reduce metal ions $[2,11]$. The primary effects of the interaction of high-energy radiation such as electron beams or gamma photons with a solution of metal ions are the excitation and the ionisation of the solvent. For example, in aqueous solutions according equation [1]:

$$
\mathrm{H}_{2} \mathrm{O} \Rightarrow \mathrm{e}^{-}, \mathrm{H}_{3} \mathrm{O}^{+}, \mathrm{H}^{\bullet}, \mathrm{OH}^{\bullet}, \mathrm{H}_{2}, \mathrm{H}_{2} \mathrm{O}_{2}
$$

Oxidation by hydroxyl radical $\mathrm{OH}^{\bullet}$ is avoided by addition of radical scavengers, such as 2-propanol which yield after reactions with $\mathrm{OH}^{\bullet}$ and $\mathrm{H}^{\bullet}$ to a secondary reducing radical $\left(\mathrm{CH}_{3}\right)_{2} \mathrm{C}^{\bullet} \mathrm{OH}$ [12]. Solvated electrons $\mathrm{e}_{\text {aq }}^{-}$and alcohol radicals are strong reducing agents capable to reduce metal ions to lower valences and finally to metal atoms.

Metal atoms formed in solution by reduction then tend to associate with other ions and coalesce into dimers. These dimers progressively grow into oligomers followed by larger clusters which eventually precipitate [13]. To obtain stable clusters, the coalescence is limited by adding a polymeric molecule acting as cluster stabiliser [2]. Radiation-induced reduction of metal ions is a powerful method to control the synthesis of mono- and multimetallic nanoparticles and supported clusters [2, 14-18]. It has been shown that the structure of bimetallic nanoparticles, such as gold-silver, gold-palladium or gold-platinum systems $[15,17-18]$, depends on the irradiation dose rate because of the competition between the radiolytic reduction and the electron transfer reaction from the less noble metal atoms to the other metal cations. At high dose rate (with electron beams), the reduction is sudden and faster than a possible inter-metal electron transfer and genuine alloyed clusters are formed. With electron beams, one can obtain very monodispersed nanoparticles and new alloys at room temperature while by gamma radiolysis, as in chemical reduction, only a few systems such as Ag-Pd were shown to yield intimately alloyed clusters. $\mathrm{Au}_{\text {core }}-\mathrm{Pd}_{\text {shell }}$ clusters were obtained by radiolytic reduction at low dose rate [17]. Au-Pd alloyed clusters were synthesised for the first time at room temperature by electron-beam radiolysis [17] while chemical reduction leads to bilayered clusters and the alloyed structures were only obtained at high temperature (up to $623 \mathrm{~K}$ ).

The nanoparticles are then suitable model systems for studying alloying effects in catalysis which is still a debated topic. Indeed, alloying induces very complex transformations of the active sites [19]: electronic effects (shift of $d$ band due to orbital hybridisation), more geometric effect by dilution, surface structure effect due to segregation or constraint phenomenon, all these effects being often closely linked which make studies of bimetallic catalysts particularly difficult. In the present work, bimetallic nanoparticles were deposited on alumina carrier, characterised in order to follow the possible modifications brought by the support on the structure of the particles, and then evaluated in selective hydrogenation of buta-1,3-diene. The effect of the cluster structure on the catalytic activity was studied.

\section{EXPERIMENTAL}

\subsection{Materials and Apparatus}

Materials: the solutions were prepared using ultra pure water from a Millipore system (18 M $\Omega . \mathrm{cm})$ and reagent grade chemicals used without further purification: $\mathrm{AgNO}_{3}$, $\mathrm{HAuCl}_{4}, \mathrm{Pd}\left(\mathrm{NO}_{3}\right)_{2}$ and poly (vinyl alcohol) (PVA, 99\% hydrolysed, $\mathrm{MW}=86000$ ) from Aldrich, 2-propanol from Prolabo and $\mathrm{HNO}_{3}$ from Acros. The solutions were stripped by bubbling with nitrogen $\left(\mathrm{N}_{2}\right.$, from Air Liquide) before irradiation. $\mathrm{Pd}\left(\mathrm{NO}_{3}\right)_{2}$ was dissolved in acidic medium $(\mathrm{pH}=1-2)$ to avoid the formation of palladium hydroxide. The $\mathrm{pH}$ was adjusted by adding $\mathrm{HNO}_{3}$. Note that in acidic medium, the solvated electrons react with $\mathrm{H}^{+}$and are replaced by the reducing $\mathrm{H}^{\bullet}$ radicals.

The alumina $\left(\gamma-\mathrm{Al}_{2} \mathrm{O}_{3}, \mathrm{~S}_{\mathrm{BET}}=130 \mathrm{~m}^{2} / \mathrm{g}\right)$, was crushed and sieved in the $63-100 \mu \mathrm{m}$ range, (porous volume of $\left.1.04 \mathrm{~mL} \cdot \mathrm{g}^{-1}\right)$.

Irradiation facilities: the $\gamma$-irradiation source was a ${ }^{60} \mathrm{Co}$ $\gamma$-facility of 7000 Curies with a dose rate of $1.75 \mathrm{~Gy}^{-1} \mathrm{~s}^{-1}(6300$ $\left.\mathrm{Gy} . \mathrm{h}^{-1}\right)$ at Orsay. Electron beam irradiations were performed with a $20 \mathrm{~kW}$ and $10 \mathrm{MeV}$ electron accelerator (CARICIonisos Society) delivering trains of $14 \mu \mathrm{s}$ pulses $(10-350 \mathrm{~Hz})$ 
through a scanning beam $(1-10 \mathrm{~Hz})$ of mean dose rate $2200 \mathrm{~Gy} \cdot \mathrm{s}^{-1}\left(7.9 \mathrm{MGy} \cdot \mathrm{h}^{-1}\right)$. This installation is currently used for medical sterilisation and food ionisation at industrial scale. The cost of electron irradiation is compensated by the added value of the irradiated products. For our experiments the solutions were irradiated in glass vessels with a rubber plastic septum.

\subsubsection{UV-Visible Spectroscopy}

UV-visible absorption spectra of clusters in solution were recorded just after irradiation with a single beam HewlettPackard 8453 spectrophotometer.

\subsubsection{Transmission Electron Microscopy (TEM)}

TEM characterisation of the irradiated solutions was carried out on a JEOL 100CXII transmission electron microscope at $100 \mathrm{kV}$. Sample drops of the irradiated solutions were deposited and dried on carbon-coated copper grids. TEM characterisation of the bimetallic particles supported on alumina was carried out on a JEOL 2010 at $200 \mathrm{kV}$. Samples were crushed in ethanol and deposited on a copper grid coated with a perforated carbon film.

\subsubsection{Elemental Analysis}

Atomic emission spectroscopy and X-ray fluorescence analysis were used to determine respectively the metal loading for $\mathrm{Pd}$ and $(\mathrm{Au}$ or $\mathrm{Ag}$ ) of the bimetallic catalysts.

\subsubsection{Catalyst Preparation}

The solutions containing metal salts - $\mathrm{Pd}\left(\mathrm{NO}_{3}\right)_{2}, \mathrm{AgNO}_{3}$, $\mathrm{HAuCl}_{4}$ - were irradiated under $\mathrm{N}_{2}$ atmosphere in the presence of poly (vinyl alcohol) as stabilising agent and isopropanol as $\mathrm{OH}^{*}$ scavenger. The typical concentrations of metal salts, PVA and isopropanol were respectively $1 \times 10^{-2}$ to $2 \times 10^{-2} \mathrm{M}, 5 \times 10^{-2}$ and $0.1 \mathrm{M}$. Note that in acidic medium, the solvated electrons after reaction with $\mathrm{H}^{+}$are replaced by the reducing $\mathrm{H}^{\bullet}$ radicals.

Genuine Au-Pd alloys (A and B catalysts) are synthesised by extremely fast reduction to prevent the electron transfer from $\mathrm{Pd}^{\mathrm{I}}$ or $\mathrm{Pd}^{\circ}$ to gold ions $\mathrm{Au}^{\mathrm{III}}$ and $\mathrm{Au}^{\mathrm{I}}$ and thus any segregation [17]. For this purpose, irradiation of mixed $\mathrm{Au}^{\mathrm{III}} / \mathrm{Pd}^{\mathrm{II}}$ solutions is achieved by electron beams.

In the case of $\mathrm{Au}-\mathrm{Pd}$ system, mixed $\mathrm{Au}{ }^{\mathrm{III}} / \mathrm{Pd}^{\mathrm{II}}$ solutions are irradiated under gamma to obtain bilayered $\mathrm{Au}_{\text {core }}-\mathrm{Pd}_{\text {shell }}$ (catalyst C) structure. Bilayered $\mathrm{Pd}_{\text {core }}-\mathrm{Au}_{\text {shell }}$ (catalyst $\mathrm{D}$ ) nanoparticles are obtained in two steps: Pd nanoparticles are first synthesised by $\gamma$ irradiation (of solutions containing $\mathrm{Pd}^{\mathrm{II}}$, PVA and isopropanol); then $\mathrm{Au}^{\mathrm{III}}$ is added to the irradiated solution and is reduced at the surface of Pd nanoparticles by radiolysis.
Genuine Ag-Pd alloys (F, G catalysts) are synthesised by gamma or by electron beams radiolysis of mixed $\mathrm{Ag}^{\mathrm{I}} / \mathrm{Pd}^{\mathrm{II}}$ solutions [16]. Bilayered $\mathrm{Ag}_{\text {core }}-\mathrm{Pd}_{\text {shell }}$ nanoparticles (H catalyst) are obtained in two steps: first Ag clusters are synthesised by irradiation of solutions containing $\mathrm{Ag}^{+}$, PVA and isopropanol and then $\mathrm{Pd}^{\mathrm{II}}$ is added to the irradiated solution and is reduced at the surface of silver clusters by gamma irradiation.

After $\gamma$ or electron-beam irradiation, the cluster containing solutions were analysed by UV-visible spectroscopy. Our previous results show that small $(2-3 \mathrm{~nm})$ and monodispersed $\mathrm{Au}-\mathrm{Pd}$ and Ag-Pd nanoparticles are obtained by irradiation of solutions containing $10^{-3} \mathrm{M}$ in metal salts and $10^{-1} \mathrm{M}$ in PVA [16-17]. For the present experiments, we have used higher metal concentrations to reduce the solution volumes and to obtain a better impregnation of the support. The sulfate counter ions were not used to avoid the poisoning of the metallic active sites during the catalytic tests.

After irradiation, the solutions were put in contact with the alumina using the excess impregnation technique under stirring for a few hours. The solutions were then centrifuged. The recorded UV-visible spectra of the solution after centrifugation indicate that almost all the metal nanoparticles were deposited on the support. The extracted catalysts containing supported nanoparticles were washed several times with water and then dried at $333 \mathrm{~K}$ in the oven drier and further reduced under pure hydrogen at $573 \mathrm{~K}$ for $2 \mathrm{~h}$ (ramp $5^{\circ} \mathrm{C} \cdot \mathrm{min}^{-1}$ ) before characterisation and catalytic evaluations.

In order to compare the catalytic properties with a catalyst prepared via a classical chemical method, we performed an incipient wetness coimpregnation of a solution containing both metals $\left(\mathrm{Pd}\left(\mathrm{NO}_{3}\right)_{2}\right.$ and $\mathrm{AgNO}_{3}$ or $\mathrm{Pd}\left(\mathrm{NO}_{3}\right)_{2}$ and $\left.\mathrm{HAuCl}_{4}\right)$ on the same alumina support than previously. These catalysts were finally calcined under air flow at $723 \mathrm{~K}$ during $2 \mathrm{~h}$ and previously reduced at $573 \mathrm{~K}$ for $2 \mathrm{~h}$ before catalytic evaluation.

\subsection{Catalytic Tests}

Buta-1,3-diene selective hydrogenation tests were performed in liquid phase using a laboratory scale stainless steel perfectly stirred batch reactor working under constant hydrogen pressure and with variation of the concentration of reactants (buta-1,3-diene) and products over time. Circa $1 \mathrm{~g}$ of catalyst reduced during $2 \mathrm{~h}$ under $\mathrm{H}_{2}$ flow at $573 \mathrm{~K}$ (heating rate $1{ }^{\circ} \mathrm{C} \cdot \mathrm{min}^{-1}$ ) were put in contact with buta-1,3-diene (about $10 \mathrm{~g})$ diluted in $\mathrm{n}$-heptane $(240 \mathrm{~mL})$ at $280 \mathrm{~K}$ under 5 bar of $\mathrm{H}_{2}$. Experimental conditions (stirring rate) were previously selected in order to avoid mass transfer limitations. The liquid reactant was sampled over time, cooled and analysed by a gas chromatographer HP5890 II equipped with a plot alumina column and a FID detector. Results are expressed in terms of reaction rate $\left(\mathrm{mol} \mathrm{H}_{2}\right.$ consumed/min/gPd) and the ratio of the diene to olefin hydrogenation rates taken in the zero order kinetic regime. 


\section{RESULTS AND DISCUSSION}

\subsection{Au-Pd Colloidal System}

Recently bimetallic Au-Pd nanoparticles have been synthesised by radiation-induced reduction of aqueous solutions of metal ions with different $\mathrm{Au}{ }^{\mathrm{III}} / \mathrm{Pd}^{\mathrm{II}}$ ratios [17]. These nanoparticles have been characterised by UV-visible spectroscopy, XPS and EDAX [17]. The evolution of the plasmon spectra and the local X-ray micro diffraction have been systematically studied as a function of irradiation dose and dose rate. At low dose rate $\left(6 \mathrm{kGy} \cdot \mathrm{h}^{-1}\right)$ (with $\gamma$ irradiation), bilayered $\mathrm{Au}_{\text {core }}-\mathrm{Pd}_{\text {shell }}$ clusters with a mean size of 3-4 nm are obtained. Due to inter-metal electron transfer from nascent Pd atoms to gold ions, the latter are reduced first and constitute mainly the core of the particle. Pd ions are finally reduced at the surface of gold clusters after the reduction of all $\mathrm{Au}^{\mathrm{III}}$ ions and core-shell particles are formed. At high dose rate $\left(2.2 \mathrm{kGy} . \mathrm{s}^{-1}\right)$ (with electron beams), very fast reduction is achieved and alloyed nanoparticles with a mean size of 2-3 nm are formed. The dose rate has an effect on the particle size: at high dose rate smaller particles are obtained with a narrow distribution in size.

The optical spectrum of a $\mathrm{Au}^{\mathrm{III}} / \mathrm{Pd}^{\mathrm{II}}$ mixed solution irradiated by gamma rays shows that gold is reduced first as the spectrum is first identical to the surface plasmon spectrum of pure gold with the specific maximum at $520 \mathrm{~nm}$, then with increasing irradiation dose the intensity continues to increase but the typical absorption maximum at $520 \mathrm{~nm}$ progressively disappears and the final spectrum is close to the plasmon of pure palladium clusters. This spectral evolution indicates indeed that the cluster composition changes when the dose increases from almost pure gold clusters to clusters coated with an increasing surface layer rich in palladium. At high dose rate irradiation obtained by electron beams, the band intensity progressively increases with dose in a similar way at any wavelength up to complete reduction. No maximum is detected at $520 \mathrm{~nm}$ even at lower doses in contrast with gamma irradiation. This indicates that palladium and gold are reduced simultaneously from the beginning of irradiation. In that case, alloyed nanoparticles are formed.

A Transmission electron microscopy micrograph of the bimetallic Au-Pd clusters obtained by electron beams (alloyed structure) in our experimental conditions (Table 1) is shown in Figure 1a. Small nanoparticles with a size of 2-3 nm are obtained, a few nanoparticules are larger up to $5 \mathrm{~nm}$. The nanoparticles obtained in this work are larger than that obtained in previous studies at lower metal concentrations $\left(10^{-3} \mathrm{M}\right)$ [17]. It is known that increasing the concentration of the initial salt orients the synthesis towards higher nuclearities.
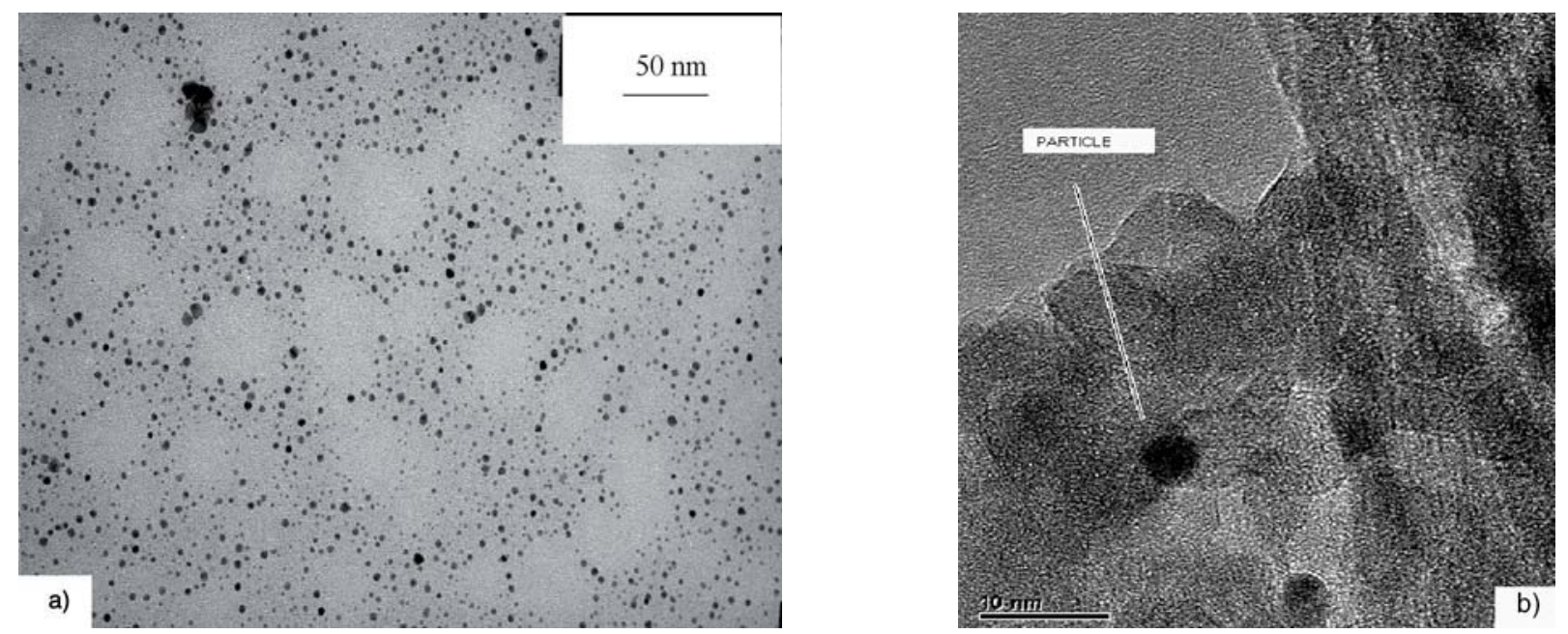

Figure 1

a) TEM Micrograph of Au-Pd bimetallic particles stabilised by Polyvinyl Alcohol (PVA) and obtained by electron beam irradiation $\left(\right.$ dose rate $\left.=7.1 \mathrm{MGy} \cdot \mathrm{h}^{-1}\right)$ of a solution containing $9 \times 10^{-3} \mathrm{M}$ of $\mathrm{Pd}\left(\mathrm{NO}_{3}\right)_{2}, 1.2 \times 10^{-3} \mathrm{M}$ of $\mathrm{HAuCl}_{4}$ and $5 \times 10^{-2} \mathrm{M} \mathrm{PVA}$. The size of the particles is 2-5 nm; b) TEM micrograph of the (B) alloyed Au-Pd catalyst after reduction at $573 \mathrm{~K}$. 

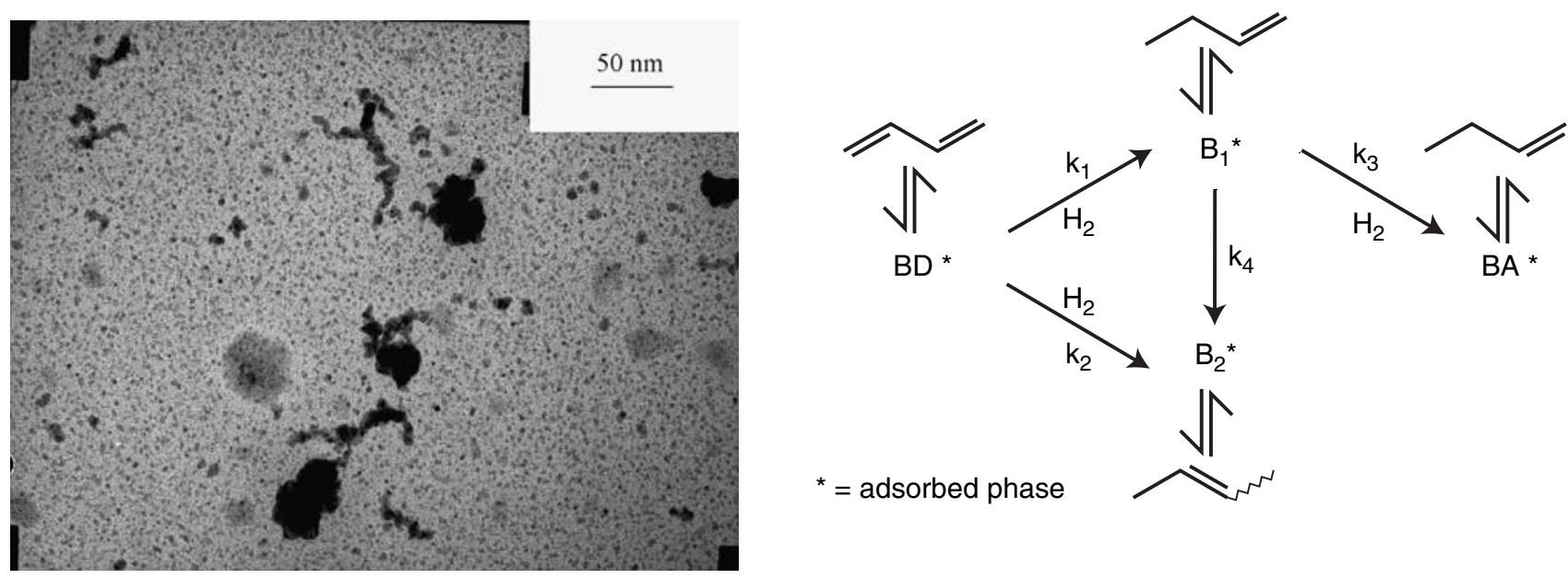

Figure 2

TEM micrograph of bimetallic alloyed Ag-Pd clusters stabilised by Polyacrylic Acid (PA) and obtained by electron beams (dose rate $=7.1 \mathrm{MGy}^{-\mathrm{h}^{-1}}$ ) of a solution containing $8 \times 10^{-3} \mathrm{M}$ of $\mathrm{Pd}\left(\mathrm{NO}_{3}\right)_{2}, 4 \times 10^{-3} \mathrm{M}$ of $\mathrm{AgNO}_{3}$ and $5 \times 10^{-2}$ $\mathrm{M}, \mathrm{PVA}$. Dose $=32 \mathrm{kGy}$.

Figure 3

Reaction network for the selective hydrogenation of 1,3 butadiene. $\mathrm{BD}=$ buta-1,3-diene, $\mathrm{B} 1$ = but-1-ene, $\mathrm{B} 2$ = but-2-enes and $\mathrm{BA}=$ butane .

TABLE 1

Conditions of synthesis of Au-Pd clusters in solution. Concentrations in mol. $\mathrm{L}^{-1}$. Dose rate in $\mathrm{kGy}$

\begin{tabular}{|c|c|c|c|c|c|}
\hline Structure & $\begin{array}{c}\text { Irradiation } \\
\text { mode/Dose rate } \\
(\mathrm{kGy})\end{array}$ & $\begin{array}{c}{[\mathrm{Pd}]} \\
\mathrm{mol} . \mathrm{L}^{-1}\end{array}$ & $\begin{array}{c}{[\mathrm{Au}]} \\
\mathrm{mol} . \mathrm{L}^{-1}\end{array}$ & $\begin{array}{l}{[\mathrm{PVA}]} \\
\mathrm{mol} . \mathrm{L}^{-1}\end{array}$ & $\begin{array}{l}{[\mathrm{iPrOH}]} \\
\mathrm{mol} . \mathrm{L}^{-1}\end{array}$ \\
\hline A Alloyed & Electrons / 34 & 7.5.10-3 & $2.03 .10^{-3}$ & $5.10^{-2}$ & 0.1 \\
\hline B Alloyed & Electrons / 34 & $9.10^{-3}$ & $1.22 .10^{-3}$ & $5.10^{-2}$ & 0.1 \\
\hline C $\mathrm{Au}_{\text {core }} \mathrm{Pd}_{\text {shell }}$ & Gamma / 32 & $9.10^{-3}$ & $1.22 .10^{-3}$ & $5.10^{-2}$ & 0.1 \\
\hline D $\mathrm{Pd}_{\text {core }} \mathrm{Au}_{\text {shell }}$ & $\begin{array}{c}\text { Gamma / } 24 \\
\text { and } 9.5\end{array}$ & $7.5 .10^{-3}$ & $2.03 .10^{-3^{*}}$ & $5.10^{-2}$ & 0.1 \\
\hline
\end{tabular}

*Addition of HAuCl4 after the first irradiation.

\subsection{Ag-Pd Colloidal System}

The characterisation by UV-visible spectroscopy and X-rays diffraction study of the Ag-Pd clusters synthesised by radiolysis was reported in a previous paper [16]. The UV-visible sprectum shapes do not change with increasing dose and the maximum absorption depends on the initial solution composition. In the case of irradiation of mixed $\mathrm{Ag}^{\mathrm{I}} / \mathrm{Pd}^{\mathrm{II}}$ solutions alloyed bimetallic nanoparticles are obtained even at low dose rate [16].

TEM micrographs of the irradiated solutions in our experimental conditions (Table 2) show small bi-metallic Ag-Pd clusters with a mean size of 2-3 nm but also few larger nanoparticles up to $5 \mathrm{~nm}$ and large flocs (Fig. 2).
TABLE 2

Conditions of synthesis of Ag-Pd clusters in solution. Concentrations in mol. $\mathrm{L}^{-1}$. Dose rate in $\mathrm{kGy}$

\begin{tabular}{|c|c|c|c|c|c|c|}
\hline & Structure & $\begin{array}{c}\text { Irradiation } \\
\text { mode/Dose rate } \\
(\mathrm{kGy})\end{array}$ & $\begin{array}{c}{[\mathrm{Pd}]} \\
\mathrm{mol} . \mathrm{L}^{-1}\end{array}$ & $\begin{array}{c}{[\mathrm{Ag}]} \\
\mathrm{mol} . \mathrm{L}^{-1}\end{array}$ & $\begin{array}{c}{[\mathrm{PVA}]} \\
\mathrm{mol} . \mathrm{L}^{-1}\end{array}$ & $\begin{array}{c}{[\mathrm{iPrOH}]} \\
\mathrm{mol}^{-\mathrm{L}^{-1}}\end{array}$ \\
\hline $\mathrm{F}$ & Alloyed & Electrons / 34 & $9.10^{-3}$ & $2.25 .10^{-3}$ & $5.10^{-2}$ & 0.1 \\
\hline G & Alloyed & Electrons / 34 & $8.10^{-3}$ & $4.10^{-3}$ & $5.10^{-2}$ & 0.1 \\
\hline $\mathrm{H}$ & $\mathrm{Ag}_{\text {core }} \mathrm{Pd}_{\text {shell }}$ & 24 and 9.5 & $8.10^{-3^{*}}$ & $4.10^{-3}$ & $10^{-2}$ & 0.1 \\
\hline
\end{tabular}

*Addition of $\mathrm{Pd}\left(\mathrm{NO}_{3}\right)_{2}$ after the first irradiation.

Characterisation and catalytic properties of $A u-P d$ and Ag-Pd clusters deposited on alumina

Compositions of the Au-Pd (alloyed, $\mathrm{Au}_{\text {core }}-\mathrm{Pd}_{\text {shell }}, \mathrm{Pd}_{\text {core }}{ }^{-}$ $\mathrm{Au}_{\text {shell }}$ samples) and $\mathrm{Ag}-\mathrm{Pd}$ (alloyed, $\mathrm{Ag}_{\text {core }}-\mathrm{Pd}_{\text {shell }}$ samples) catalysts are reported on Tables 3 and 4 . All the catalysts contain the same amount of Pd (approximately $0.19 \%$ ), with different amounts of $\mathrm{Au}(0.05$ up to $0.13 \%)$ and $\mathrm{Ag}(0.04$ to $0.1 \%)$.

Buta-1,3-diene hydrogenation is a widely used model reaction to investigate surface modification by promoters or alloy formation [20]. The mechanism of the reaction observed for Pd surface is usually described by the pathway presented in Figure 3 [21-22]. Due to its stronger adsorption coefficient, buta-1,3-diene is firstly hydrogenated into but-1-ene and trans/cis but-2-enes (primary products) and after complete consumption of buta-1,3-diene, but-1-ene is then hydrogenated into butane or isomerised 
TABLE 3

Characterisation of the Au-Pd supported clusters prepared using the radiolytic technique

\begin{tabular}{c|c|c|c}
\hline & Structure & $\%$ wt Pd & $\%$ wt Au \\
\hline $\mathrm{A}$ & Alloyed & 0,19 & 0,13 \\
\hline $\mathrm{B}$ & Alloyed & 0,19 & 0,06 \\
\hline $\mathrm{C}$ & $\mathrm{Au}_{\text {core }}-\mathrm{Pd}_{\text {shell }}$ & 0,19 & 0,05 \\
\hline $\mathrm{D}$ & $\mathrm{Pd}_{\text {core }}-\mathrm{Au}_{\text {shell }}$ & 0,19 & 0,05 \\
\hline
\end{tabular}

into but-2-enes. But-2-enes are finally converted into butane with a much lower rate.

The catalytic properties of supported Au-Pd clusters with alloyed or core-shell structures compared to a conventional catalyst are reported in Table 5.

The alloyed Au-Pd catalysts (A, B) are significantly more active than the core-shell ones $(\mathrm{C}, \mathrm{D})$. Indeed, the activities are enhanced by a factor 10 , and are even higher than that of the conventional catalyst. This activity enhancement seems not to be correlated to the weight percent of $\mathrm{Au}$ (comparison between catalysts $\mathrm{B}$ and $\mathrm{C}$ ).

The different sizes between the particles of the alloyed samples synthesised under electron irradiation $(2-3 \mathrm{~nm}$,
Fig. 1a), and the core-shell samples synthesised under $\gamma$ irradiation (3-4 nm) previously observed [17] in solution, cannot explain the enhancement of the catalytic activities. Moreover, TEM characterization of the supported alloyed Au-Pd particles (catalyst B) carried out after impregnation and thermal treatment at $573 \mathrm{~K}$ under $\mathrm{H}_{2}$ (Fig. 1 b) shows bimetallic particles with a size comprised in the range $2-5 \mathrm{~nm}$, and a mean particle size of $3 \mathrm{~nm}$. The size distribution of the supported bimetallic Au-Pd particles is in agreement with the size distribution observed for the Au-Pd clusters in solution. So, the mean particle size determined in solution is kept for the supported clusters after reduction at $573 \mathrm{~K}$. The corresponding variation in terms of exposed metallic surface area between alloyed or core-shell catalysts is not higher than 2 , taking into account the respective values of dispersion (fraction of exposed atoms). Thus the enhancement of the catalytic activity is more probably due to differences in terms of surface structures and composition between alloyed and core-shell samples rather than a direct size effect.

The core-shell catalysts $(\mathrm{C}, \mathrm{D})$, with $\mathrm{Pd}$ on the surface (sample $\mathrm{C}$ ) or $\mathrm{Au}$ on the surface (sample D), have quite the same activity. It has been shown that the preparation of $\mathrm{Au}_{\text {core }}-\mathrm{Pd}_{\text {shell }}$ clusters is possible using the radiolytic technique even if the segregation of Pd on the surface is not predicted by the available thermodynamic data [23] because of the lower surface energy of $\mathrm{Au}\left(\gamma=1.5 \mathrm{~J}^{-2} \mathrm{~m}^{-2}\right)$ compared to $\mathrm{Pd}$

TABLE 5

Catalytic performances of the bimetallic Au-Pd supported clusters prepared using the radiolytic technique.

Reaction rate $\mathrm{k}_{\mathrm{BD}}, \mathrm{k}_{\text {but-1-ene }}$ reported in mol. $\mathrm{min}^{-1} \cdot \mathrm{gPd}^{-1}$. Selectivity in but-1-ene observed at $80 \%$ conversion of buta-1,3-diene

\begin{tabular}{|c|c|c|c|c|c|c|c|}
\hline & Structure & \%wt Pd & $\%$ wt Au & $\begin{array}{c}\text { Reaction rate } \\
\left(\mathrm{k}_{\mathrm{BD}}\right)\end{array}$ & $\begin{array}{c}\text { Reaction rate } \\
\left(\mathrm{k}_{\text {but-1-ene }}\right)\end{array}$ & $\begin{array}{c}\text { Selectivity } \\
\left(\mathrm{k}_{\mathrm{Bd}} / \mathrm{k}_{\text {but-1-ene }}\right)\end{array}$ & but-1-ene $(\%)$ \\
\hline $\begin{array}{c}\text { Conventional } \\
\text { catalyst }\end{array}$ & Alloyed & 0,20 & 0,10 & 19,0 & 2.7 & 7.0 & 59.6 \\
\hline A & Alloyed & 0,19 & 0,13 & 24.5 & 5.2 & 4.7 & 62.7 \\
\hline B & Alloyed & 0,19 & 0,06 & 30.5 & 4.2 & 7.3 & 62.3 \\
\hline $\mathrm{C}$ & $\mathrm{Au}_{\text {core }}-\mathrm{Pd}_{\text {shell }}$ & 0,19 & 0,05 & 2.4 & 0.3 & 8.6 & 61.1 \\
\hline D & $\mathrm{Pd}_{\text {core }}-\mathrm{Au}_{\text {shell }}$ & 0,19 & 0,13 & 2.6 & 0.3 & 9.8 & 58.9 \\
\hline
\end{tabular}

TABLE 6

Catalytic performances of the bimetallic Ag-Pd supported clusters prepared using the radiolytic technique. Reaction rate $\mathrm{k}_{\mathrm{BD}}, \mathrm{k}_{\text {but-1-ene }}$ reported in mol. $\mathrm{min}^{-1} \cdot \mathrm{gPd}^{-1}$. Selectivity in but-1-ene observed at $80 \%$ conversion of buta-1,3-diene

\begin{tabular}{c|c|c|c|c|c|c}
\hline & Structure & $\%$ wt Pd & $\%$ wt Ag & $\begin{array}{c}\text { Reaction rate } \\
\left(\mathrm{k}_{\mathrm{BD}}\right)\end{array}$ & $\begin{array}{c}\text { Reaction rate } \\
\left(\mathrm{k}_{\text {but-1-ene }}\right)\end{array}$ & 0.5 \\
\hline $\begin{array}{c}\text { Conventional } \\
\text { catalyst }\end{array}$ & Alloyed & 0,2 & 0,10 & 5.0 & 6.3 \\
\hline $\mathrm{F}$ & Alloyed & 0,19 & 0,04 & 6.6 & 0.5 & 0.3 \\
\hline $\mathrm{G}$ & Alloyed & 0,18 & 0,06 & 5.6 & 6.4 \\
\hline $\mathrm{H}$ & $\mathrm{Ag}_{\text {core }}-\mathrm{Pd}_{\text {shell }}$ & 0,17 & 0,06 & 5.8 & 0.9 & 18.7 \\
\hline
\end{tabular}


$\left(\gamma=2.0 \mathrm{~J}^{\mathrm{m}} \mathrm{m}^{-2}\right)[24]$. Nevertheless, before measuring the catalytic properties of the catalysts in hydrogenation of buta-1,3-diene, the catalyst were activated under $\mathrm{H}_{2}$ at $573 \mathrm{~K}$. Gold has a very low fusion temperature and is therefore expected to be very mobile and to diffuse very easily, even at low temperature [25]. This thermal activation could induce relaxation and reconstruction phenomena in the particle, leading to a state closer to the thermodynamic equilibrium state for both samples, thus with Au segregation on the cluster surface as reported in literature [26]. As a consequence, after this thermal treatment, the clusters deposited on alumina should all exhibit the same surface structure whatever the initial structure, with a low proportion of Pd on the particle surface. Additionally, the adsorption energy of buta-1,3-diene, very strong on $\mathrm{Pd}$ compared to $\mathrm{Au}$, can also induce additional surface reconstruction via $\mathrm{Pd}$ extraction from sub-surface layers during the catalytic reaction.

If reconstruction proceeds in the same extent for all the catalysts, the variations of activity between the catalysts A, B (alloyed PdAu), C and D (core shell structures) should follow the variations of particle size. However, the $C$ and $D$ catalysts have a much lower activity when compared to the alloyed $\mathrm{A}$ and B samples, not compatible with the difference of particle sizes as already mentioned. This large variation could be explained by different surface compositions. Indeed, equilibrated surface structure and composition are very sensitive to particle size and may be very different between $\mathrm{C}$ and $\mathrm{D}$ catalysts containing larger particles (3-4 nm) and A and B catalysts with smaller ones $(2-3 \mathrm{~nm})$. As shown by theoretical calculations [27] segregation phenomenon is expected to occur in a higher extent for larger particles ( $\mathrm{C}$ and $\mathrm{D}$ catalysts) than smaller ones (catalysts $\mathrm{A}$ and $\mathrm{B}$ ) also because of the limited amount of element tending to segregate in small particles. As a consequence, a lower proportion of $\mathrm{Pd}$ atoms (the active element for hydrogenation in our conditions) is expected to be present on the surface due to Au segregation phenomenon, on the $\mathrm{C}$ and $\mathrm{D}$ catalyst leading to a lower catalytic activity. In any cases, no effect on the selectivity of the reaction is observed as if only the number of active sites changes and not their nature. In the case of $\mathrm{Au}-\mathrm{Pd}$ catalysts, catalytic results are compatible with ensemble effect or dilution of Pd surface by Au atoms without variations of intrinsic properties of Pd atoms.

The catalytic properties of supported Ag-Pd catalysts with alloyed or core-shell structures are reported in Table 6 and a comparison between $\mathrm{Ag}-\mathrm{Pd}$ alloyed ( $\mathrm{G}$ catalyst) and the bimetallic reference catalyst is given in Figure 4. No significant difference in catalytic activity in hydrogenation of buta1,3-diene is observed between the alloyed, core-shell or reference Ag-Pd catalysts. Nevertheless, concerning the consecutive reaction (olefins saturation), we notice the very low activity in butenes hydrogenation of the alloyed Ag-Pd (G) catalyst, which has the highest selectivity as shown by the high ratio of reaction rate $\mathrm{k}_{\mathrm{Bd}} / \mathrm{k}_{\text {but-1-ene }}=18.7$. This important feature may be associated with a better interaction between the two elements than in the case of the conventional catalyst and probably to a different surface composition. On the other hand, the results obtained with the $\mathrm{Ag}_{\text {core }}-\mathrm{Pd}_{\text {shell }}(\mathrm{H})$ catalyst are not significantly different from the conventional catalyst.

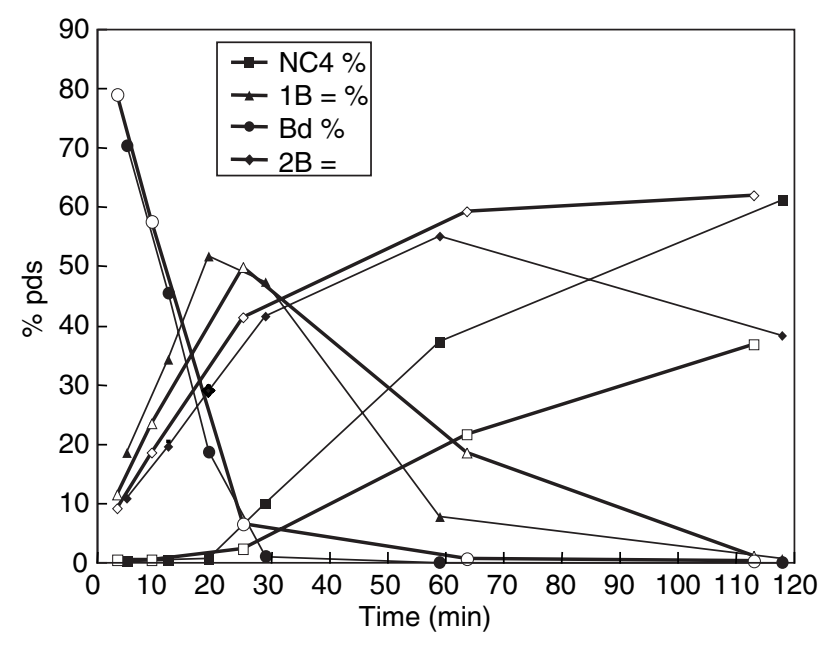

Figure 4

Comparison of catalytic results of reference Ag-Pd (full symbols) and Ag-Pd alloyed G catalyst (empty symbols).

TEM characterisation of the more selective sample $(\mathrm{G})$ was carried out to get more information about the structure of the Ag-Pd particles after the thermal treatment under hydrogen at $573 \mathrm{~K}$. Actually, Ag has similar thermodynamic properties (very low fusion temperature, high mobility even at low temperature, low surface energy) than Au. Thus, the same behaviour under thermal treatment could be expected. The Ag segregation at the particle surface should be even more pronounced since the surface energy of $\mathrm{Ag}(\gamma=$ $1.25 \mathrm{~J}^{-2} \mathrm{~m}^{-2}$ ) is lower than Au. The supported (G) sample, after reduction at $573 \mathrm{~K}$, shows only bimetallic particles with a mean size centred around $10 \mathrm{~nm}$, and included in the range 5-18 nm. On HRTEM images (Fig. 5), no core-shell structure is evidenced, the Ag-Pd particles are thus probably fully alloyed. The HRTEM characterisation of the $\mathrm{Ag}_{\text {core }}-\mathrm{Pd}_{\text {shell }}$ (H) sample was also carried out to be sure of the feasibility of the HRTEM technique to distinguish alloyed or core-shell structure. TEM characterisation of the $\mathrm{Ag}_{\text {core }}-\mathrm{Pd}_{\text {shell }}(\mathrm{H})$ catalyst after reduction at $573 \mathrm{~K}$ shows only bimetallic particles with a size included in the range 7-35 $\mathrm{nm}$. The size distribution of the supported particles, for the $(\mathrm{G})$ and $(\mathrm{H})$ samples, is included in the range $5-35 \mathrm{~nm}$ and is coherent with the size distribution observed for the Ag-Pd clusters in solution (mean particle size is centred around $5 \mathrm{~nm}$ with presence of larger aggregates). The HRTEM study (Fig. 6) allows to 


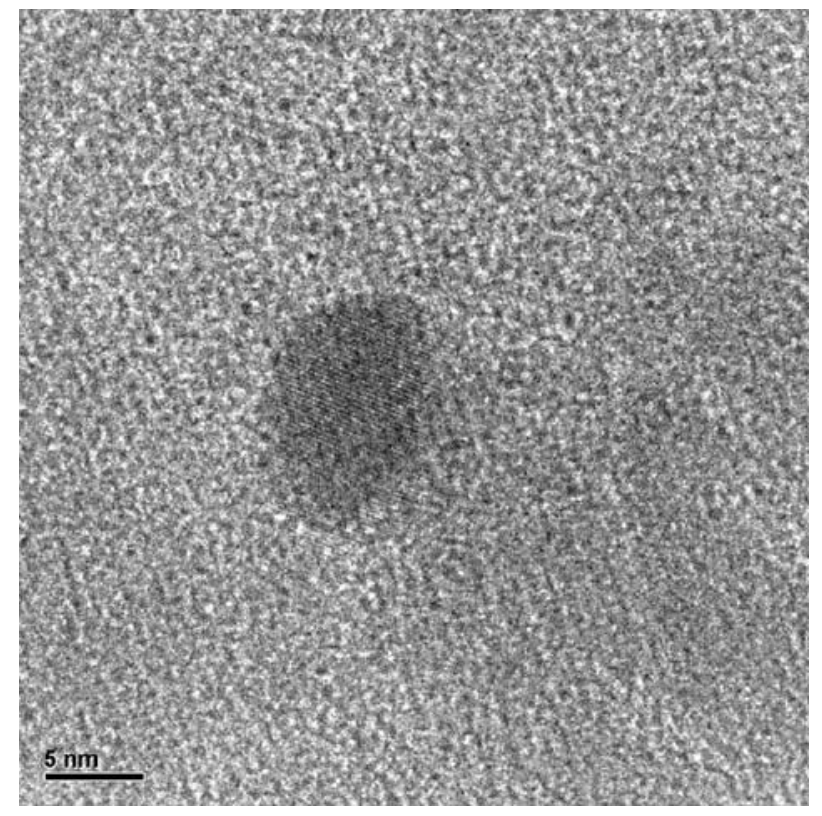

Figure 5

TEM micrograph of the $(\mathrm{G})$ alloyed Ag-Pd catalyst after reduction at $573 \mathrm{~K}$.

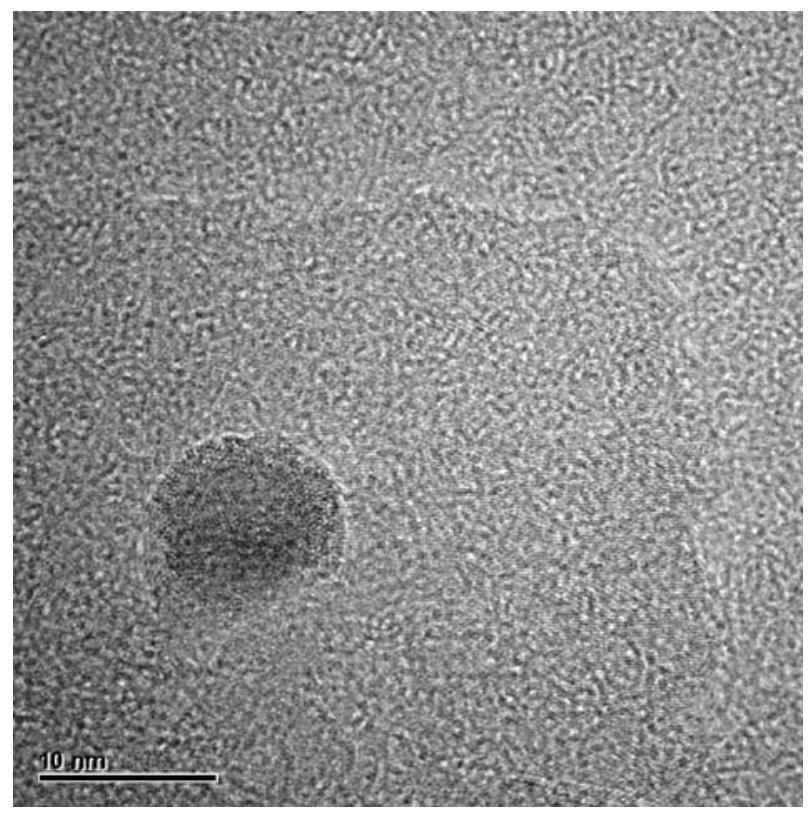

Figure 6

TEM micrograph of the $(\mathrm{H}) \mathrm{Ag}_{\text {core }}-\mathrm{Pd}_{\text {shell }}$ catalyst after reduction at $573 \mathrm{~K}$ observe a core-shell structure. Although it is not possible to distinguish the crystallographic planes of $\mathrm{Ag}$ from the $\mathrm{Pd}$ ones because their cell parameters are too close $(\mathrm{a}=0.388 \mathrm{~nm}$ for Pd and $\mathrm{a}=0.408 \mathrm{~nm}$ for $\mathrm{Ag}$ ) to be resolved due to the resolution of the microscope, a core shell structure is clearly observed by the differences of contrast between the shell and the particle core. Supported Ag-Pd alloyed particles and $\mathrm{Ag}_{\text {core }}-\mathrm{Pd}_{\text {shell }}$ particles are then evidenced showing that the initial structure observed in solution is kept after deposition on the support and thermal activation. This result shows that the bimetallic structure of small supported clusters does not follow the theoretical calculations for surface segregation determined for extended surface which predict a large enrichment of the surface by Ag [27].

The enhanced selectivity toward alkenes observed in the selective hydrogenation of buta-1,3-diene has already been reported in literature in the case of Ag-Pd catalysts [28]. This result could be related to variations of electronic properties of the Pd surface atoms due to the presence of $\mathrm{Ag}$ surface atoms. Actually, alloying Pd with Ag induces electronic modifications of the d-band valence orbitals, with a $d$ band filling of group VIII metal [29] and a shift to lower linear CO band frequency [30-31]. This effect usually called "ligand effect" can be the reason of the enhancement of the selectivity by a preferential destabilisation of alkene compared to diene adsorption. In this work, the enhancement of the selectivity observed for the Ag-Pd alloyed catalysts synthesised with radiolytic reduction of the metallic precursors, can be ascribed to a better control of the physico-chemical characteristics (size, surface composition) of the supported particles than in the case of the conventional coimpregnation method of mineral precursors.

In the case of the $\mathrm{Ag}_{\text {core }}-\mathrm{Pd}_{\text {shell }}$ (H catalyst), no effect of this original structure is observed in our catalytic results. The formation of several Pd layers does not generate particular surface site as it was observed for extended surfaces for different alloys [25].

\section{CONCLUSION}

Radiolysis is a clean process to synthesise metal nanoparticles with controlled composition and structure. Pd based catalysts (Pd, Ag-Pd and Au-Pd, alloyed or bilayered) were synthesised by electron beam or $\gamma$ radiolysis and then deposited on alumina. Selective hydrogenation of buta1,3-diene was performed using these different catalysts.

$\mathrm{Au}-\mathrm{Pd}$ bimetallic system exhibits different activities depending on the clusters structure and surface composition of the particle. The catalytic results are in good agreement with a dilution effect of Pd atoms at the surface of the particle. This Pd enrichment of the surface is particle size 
dependent and occurs without deep modifications of the electronic properties of Pd atoms. On the other hand, Ag-Pd bimetallic clusters produced by electron-beams exhibit an alloyed structure with a high selectivity toward butenes formation when compared to conventional bimetallic catalysts prepared by chemical methods. These results are compatible with a ligand effect for the Ag-Pd catalysts with modification of electronic properties. The radiolytic technique appears as a powerful tool able to control important parameters of supported particles involved in catalysis such as particle size, surface composition and bimetallic structures.

\section{ACKNOWLEDGEMENT}

The authors acknowledge P. Beaunier, Laboratoire de Réactivité de Surfaces, Université Paris VI, for additional TEM studies.

\section{REFERENCES}

1 Sinfelt, J.H. (1983) Bimetallic Catalysts-Discoveries, Concepts and Applications, Exxon Monograph, Wiley, New York.

2 Belloni, J., Mostafavi, M., Remita, H., Marignier, J.L. and Delcourt, M.O. (1998) New J. Chem., 22, 1239.

3 Ponec,V. and Bond, G.C. (Eds) (1995) Catalysis by Metal and Alloys, Elsevier, Amsterdam.

4 Guczi, L. and Gates, B.C. (1986) in Metal Cluster in Catalysis, Knözinger, H. and Guczi L. (Eds), Elsevier, Amsterdam, Chapter 10, 547.

5 Sarkany, A., Horvath, A. and Beck, A. (2002) Appl. Catal. A-Gen., 229, 117.

6 Venezia, A.M., La Parola, V., Nicoli, V. and Deganello, G. (2002) J. Catal., 212, 56.

7 Bond, G.C. and Rawle, A.F. (1996) J. Mol. Catal. AChem., 109, 261.

8 Sales, E.A., Mendes, M.J. and Bozon-Verduraz, F. (2000) J. Catal., 195, 96.

9 Landon, P., Collier, P.J., Papworth, A.J., Kiely, C.J. and Hutchings, G.J. (2002) Chem. Commun., 2058.

10 Bonarowska, M., Pielaszek, J., Semikolenov, V.A. and Karpinsky, Z. (2002) J. Catal., 209, 528.
11 Henglein, A. (1993) J. Phys. Chem., 97, 5457.

12 Buxton, G.V., Greenstock, C.L., Helman, W.P. and Ross, A.B. (1988) J. Phys. Chem., Ref. Data 17, 513.

13 Mostafavi, M., Marignier, J.L., Amblard, J. and Belloni, J. (1989) Radiat. Phys. Chem., 34, 605.

14 Gachard, E., Remita, H., Khatouri, J., Belloni, J., Keita, B. and Nadjo, L. (1998) New. J. Chem., 22, 1257.

15 Tréger, M., de Cointet, C., Remita, H., Khatouri, J., Mostafavi, M., Amblard, J., Belloni J. and De Keyser, R. (1998) J. Phys. Chem. B, 102, 4310.

16 Remita, H., Khatouri, J., Tréger, M., Amblard, J. and Belloni, J. (1997) Z. Phys. D, 40, 127.

17 Remita, H., Etchebery, A. and Belloni, J. (2003) Dose rate effect on gold-palladium bimetallic structure, J. Phys. Chem. $B, \mathbf{1 0 7}, 31$.

18 Remita, H., Lampre, I., Mostafavi, M., Balanzat, E. and Bouffard, S. (2005) Radiat. Phys. Chem., 72, 575.

19 Guczi, L. (2005) Catal. Today, 101, 53.

20 Ponec, V. and Bond, G.C. (1995) Catalysis by Metals and Alloys, Elsevier, Amsterdam, 500.

21 Goetz, J., Murzin, D.Y., Ulischenko, M. and Touroude, R. (1996) Chem. Eng. Sci., 51, 2879.

22 Boitiaux, J.P., Cosyns, J., Derrien, M. and Léger, G. (1984) AIChE National Meeting, Houston.

23 Ruban, A., Skriver, H.L. and Norskov, J.K. (1999) Phys. Rev. $B, \mathbf{5 9}, 15990$.

24 Tyson, W.R. and Miller, W.R. (1977) Surf. Sci., 62, 267.

25 Bertolini, J.C. and Jugnet, Y. (2002) The chemical physics of solid surfaces, Elsevier, 404.

26 Jablonski, A., Overbury, S.H. and Somorjai, G.A. (1977) Surf. Sci., 65, 57.

27 Rousset, J.L., Bertolini, J.C. and Miegge, P. (1996) Phys. Rev. B, 53, 4947.

28 Hightower, J.W., Furlong, B., Sarkany, A. and Guczi, L. (1993) New Frontiers in Catalysis, Guczi L. et al. (Eds.), Elsevier, Proc of 10th ICC.

29 Sinfelt, J.H. (1977) Accounts Chem. Res., 10, 15.

30 Coq, B. and Figueras, F. (2001) J. Mol. Catal. A-Chem., 173, 117.

31 Soma-Noto, Y. and Sachtler, W.M.H. (1974) J. Catal., 32, 215.

Copyright (C) 2006 Institut français du pétrole

Permission to make digital or hard copies of part or all of this work for personal or classroom use is granted without fee provided that copies are not made or distributed for profit or commercial advantage and that copies bear this notice and the full citation on the first page. Copyrights for components of this work owned by others than IFP must be honored. Abstracting with credit is permitted. To copy otherwise, to republish, to post on servers, or to redistribute to lists, requires prior specific permission and/or a fee: Request permission from Documentation, Institut français du pétrole, fax. +33147527078 , or revueogst@ifp.fr. 